\title{
Brush cytology and biopsy in the diagnosis of malignancy of gastrointestinal tract - A comparative study
}

\author{
Ojha $\mathbf{S}^{1}$, Naik $\mathbf{L}^{2}$, Fernandes $\mathbf{G}^{3}$, Joshi $\mathrm{A}^{4}$, Kothari $\mathbf{K S}^{5}$ \\ ${ }^{1}$ Dr Sandeep Ojha, Assistant professor, Department of Pathology, Chirayu Medical College and Hospital Bhopal, ${ }^{2}$ Dr \\ Leena Naik, Professor Department of Pathology, Seth G.S Medical College and KEM Hospital Mumbai, ${ }^{3}$ Dr Gwendolyn \\ Fernandes, Associate Professor, Department of Pathology, Seth G.S Medical College and KEM Hospital Mumbai, ${ }^{4}$ Dr \\ Amita Joshi, Professor Department of Pathology, Seth G.S Medical College and KEM Hospital Mumbai, ${ }^{5}$ Dr Kothari \\ K.S, Associate Professor Department of Pathology, Seth G.S Medical College and KEM Hospital Mumbai, India
}

Address for correspondence: Dr Sandeep Ojha, Email: roshanchanchlani@gmail.com

\begin{abstract}
Background: Since the introduction of image guided brush cytology in the mid1970s, the utilization of this technique has proliferated. So, currently it is the most frequently performed procedure in interventional radiology. Depending on the site of lesion, the diagnostic yield is $80 \%-95 \%$ and the complication rate is less than $2 \%$. Material and Methods: It was a cross sectional study conducted in the pathology department, KEM Hospital, Mumbai, Cytology database were searched for all patients undergoing endoscopic guided brush cytology sampling of gastrointestinal lesions during the twenty six month period January 2009 to March 2011. A total of 200 cases identified where endoscopic guided brush cytology of gastrointestinal lesions was done and their cytology slides were retrieved and reviewed. Results: Cytological diagnosis proved to be effective in confirming the diagnosis as malignancy in 102 patients (56.3\%) while 11 cases were reported as suspicious for malignancy, 19 cases (10.5\%) were reported as inadequate or not suitable for opinion, 39 cases $(21.5 \%)$ have been reported has negative for malignancy. Conclusion: Brush cytology is a safe, easy and rapid method of diagnosing gastric malignancies. It is a useful adjunct in the diagnosis of gastric malignancies and should be considered as a routine method in combination with biopsy. Multiple repeated endoscopies are recommended in cases of positive cytology and negative biopsy to rule out or confirm malignancy.
\end{abstract}

Keywords: Brush Cytology, GIT Malignancy, Sensitivity, Specificity

\section{Introduction}

Gastrointestinal (GI) cancer is one of the most common malignancies and is amongst the leading causes of death. In India, according to national cancer registry, esophageal and gastric cancers are the most common cancers found in men [1]. Since the introduction of image guided brush cytology in the mid1970s, the utilization of this technique has proliferated. So, currently it is the most frequently performed procedure in interventional radiology [2]. Depending on the site of lesion, the diagnostic yield is $80 \%-95 \%$ and the complication rate is less than $2 \%$ [3].

The clinical utility of brush cytology continues to improve in direct proportion to the increasing

Manuscript received: $25^{\text {th }}$ Sept 2015

Reviewed: $30^{\text {th }}$ Sept 2015

Author Corrected: $17^{\text {th }}$ Oct 2015

Accepted for Publication: $30^{\text {st }}$ Oct 2015 sophistication of imaging techniques and the growing experience of radiologists, cytopathologists and endoscopists. It is useful in narrow, strictured lesions where access to the tumor by the biopsy forceps is limited and broader surface area can be accessed as compared to biopsy [4].Brushing can yield near-tissueequivalent diagnostic material that can form the basis for therapeutic decisions. Minimal morbidity, low cost, and a rapid turnaround time that reduces patient anxiety make adjuvant brush cytology along with biopsy, a preferred method in the evaluation of gastrointestinal malignancy [5].Cytological examination of esophageal brushings is now considered as a highly accurate and reliable technique for the detection of malignant neoplasms of the esophagus with sensitivity and specificity between $90 \%$ - 96\% [6-8].

\section{Material and Methods}


The cytopathology databases of the pathology department, KEM Hospital, Mumbai, were searched for all patients undergoing endoscopic guided brush cytology sampling of gastrointestinal lesions during the twenty six month period January 2009 to March 2011.

In total, 200 cases were identified were endoscopic guided brush cytology of gastrointestinal lesions was done over the above twenty six month period and their cytology slides were retrieved and reviewed. Further, in all cases wherever the follow up histopathology (biopsy) material available, the corresponding slides were retrieved, reviewed and compared with the cytopathology database.

Data sheet was completed for each patient detailing Age, Sex, Symptomatology, Clinical features and Impression, Ultrasound findings and Provisional Diagnosis, Endoscopic findings - Level of the Lesion, Type of lesion and Impression, Subsequent course of the disease and follow up wherever available, Cytology Diagnosis, along with other features such adequacy, cellularity, background, anaplasia, necrosis and other artifacts, Follow up biopsy/ histopatholgy report.

In patients undergoing endoscopy, the cytological material was collected as brush by the endoscopist under the guidance of endoscopy (video assisted) from the representative lesion. The brush was removed out, rolled and spread over glass slides as smears, by the endoscopist. Sometimes if simultaneous biopsy was performed then the endoscopist prepared a touch imprint smear of the biopsied tissue or a small tiny tissue bit was crushed under another glass slide to get a crush smear. Half the number of slide smears were immediately fixed in isopropyl alcohol for about 30 minutes and the remaining were air-dried and then sent to the cytopathology section. The air dried slides were then fixed and stained with Giemsa stain and the wet fixed slides were stained with Papanicolaou stains and examined.

Evaluation of cytology results was based on the following criteria. We subdivided the results of 111 cytology specimens in 4 categories:

1. Positive for malignancy,

2. Suspicious of malignancy,

3. Negative (or benign) results, and

4. Material unsatisfactory for interpretation
Gold standard was the result of endoscopic or surgical biopsy. The sensitivity, specificity, and predictive value were calculated based on the total number of available cytology specimens.

\section{Results}

In our study, patients with suspected gastrointestinal malignancies who underwent endoscopic guided brush cytology sampling, majority were more than $50 \mathrm{yrs}$ of age (126 cases out of 211). In our study, 71 patients $(66.4 \%)$ out of 107 cases of proven gastrointestinal tract malignancy were above the age of 50 years, which is in concordance to age distribution with that reported elsewhere in the world literature. Our study had four patients who had been diagnosed to have oesophageal carcinoma (2 patients) and gastric adenocarcinoma (2 patients) respectively in their early thirties.

Gastrointestinal Tract malignancies occur predominantly in men (male to female ratio is $3-7: 1$ ) except for biliary tract malignancies where there is female preponderance (M: $\mathrm{F}$ is $1: 3)$.

Our study found gender incidence of 1.74:1 (male: female) for Gastrointestinal tract malignancies except for biliary tract malignancies which had male to female ratio 1:1. Patients with age group above 50 yrs with slight male preponderance are commonest group to undergo endoscopic brush cytology $(59.7 \%)$ and also to be diagnosed $(66.4 \%)$ with gastrointestinal malignancies.

The one of the aim of our study was to test the reliability of the endoscopic guided brush cytology technique in detecting malignancy in a group of patients with features of malignancy both clinically and endoscopically.

Among 211 patients, 181 (85.7\%) patients had lesions which appeared malignant endoscopically and material suitable for cytologic assessment was obtained in 162 cases $(89.5 \%)$.

Cytological diagnosis proved to be effective in confirming the diagnosis as malignancy in 102 patients $(56.3 \%)$ while 11 cases were reported as suspicious for malignancy, 19 cases $(10.5 \%)$ were reported as inadequate or not suitable for opinion, 39 cases (21.5\%) have been reported has negative for malignancy which could be explained by non representative area samplings. 
Among 21 cases which were reported as suspicious on endoscopy, 4 turned out to be malignant, and one case out of 9 cases reported as non neoplastic was malignant.

Table No 1: Frequency distribution of cytology diagnosis of 211 patients with endoscopic brush cytology

\begin{tabular}{|c|c|c|c|c|c|c|}
\hline Diagnostic Category & $\begin{array}{l}\text { Positive for } \\
\text { malignancy }\end{array}$ & $\begin{array}{l}\text { Susp for } \\
\text { malignacy }\end{array}$ & $\begin{array}{l}\text { Atypical } \\
\text { cells }\end{array}$ & $\begin{array}{l}\text { Negative for } \\
\text { malignancy }\end{array}$ & $\begin{array}{l}\text { Unsatisfactory } \\
\text { or Inadequate }\end{array}$ & Total \\
\hline Oesophagus & 52 & 6 & 8 & 20 & 6 & 92 \\
\hline Stomach & 24 & 2 & 3 & 20 & 2 & 51 \\
\hline $\begin{array}{l}\text { Biliary tree } \\
\text { \& small intestine }\end{array}$ & 12 & 3 & 0 & 13 & 8 & 36 \\
\hline Large Intestine & 19 & 1 & 0 & 5 & 7 & 32 \\
\hline Total & 107 & 12 & 11 & 58 & 23 & 211 \\
\hline
\end{tabular}

Table 2: Comparison of Endoscopic and Endoscopy Guided Brush cytology diagnosis of 211 patients.

\begin{tabular}{|l|l|l|l|l|l|l|}
\hline \multicolumn{2}{|l|}{ Endoscopic diagnosis } & \multicolumn{6}{l|}{ Brush cytology diagnosis } \\
\cline { 3 - 8 } \multicolumn{2}{|l}{} & Malignant & Benign & Suspicious & Atypical cells & Inadequate \\
\hline Malignant & $\mathbf{1 8 1}$ & 102 & 39 & 11 & 10 & 19 \\
\hline Suspicious & $\mathbf{2 1}$ & 4 & 12 & 1 & 1 & 3 \\
\hline Non neoplastic & $\mathbf{9}$ & 1 & 7 & 0 & 0 & 1 \\
\hline Total & $\mathbf{2 1 1}$ & $\mathbf{1 0 7}$ & $\mathbf{5 8}$ & $\mathbf{1 2}$ & $\mathbf{1 1}$ & $\mathbf{2 3}$ \\
\hline
\end{tabular}

Table 3: Comparison of Endoscopy Guided Brush cytology with the corresponding biopsy histology in 157 patients

\begin{tabular}{|l|l|l|l|l|l|}
\hline $\begin{array}{l}\text { Cytology/ Histology } \\
\text { Diagnosis }\end{array}$ & $\begin{array}{l}\text { Positive for } \\
\text { Malignancy } \\
\text { inboth Cytology } \\
\text { \& Histology }\end{array}$ & $\begin{array}{l}\text { Positive for } \\
\text { malignancy in } \\
\text { Cytology and } \\
\text { negative in } \\
\text { Histology } \\
\text { (False positive) }\end{array}$ & $\begin{array}{l}\text { Negative for } \\
\text { malignancy in } \\
\text { Cytology and } \\
\text { positive in } \\
\text { Histology } \\
\text { (False negative) }\end{array}$ & $\begin{array}{l}\begin{array}{l}\text { Negative for } \\
\text { malignancy in } \\
\text { both Cytology } \\
\text { and Histology }\end{array} \\
\text { (True positive) }\end{array}$ & $\begin{array}{l}\text { Total } \\
\text { Truegative) }\end{array}$ \\
\hline Esophagus & 48 & -- & 11 & 22 & 81 \\
\hline Stomach & 23 & 1 & 8 & 10 & 42 \\
\hline Colon & 15 & -- & 5 & 7 & 27 \\
\hline Biliary tree\&Duodenum & 3 & -- & 1 & 3 & 7 \\
\hline Total & $\mathbf{8 9}$ & $\mathbf{1}$ & $\mathbf{2 5}$ & $\mathbf{4 2}$ \\
\hline
\end{tabular}

Note: 4 cases diagnosed as positive on cytology and negative on histology were included under true positive after reviewing the slides, which were showing malignant cells.

Sensitivity $=\mathrm{TP} /$ total positive $=89 / 114(78.07 \%)$

Specificity $=\mathrm{TN} /$ total negative $=42 / 43(97.7 \%)$

Positive predictive value $=\mathrm{TP} / \mathrm{TP}+\mathrm{FP}=89 / 90(98.9 \%)$

Negative predictive value $=\mathrm{TN} / \mathrm{TN}+\mathrm{FN}=42 / 67(62.7 \%)$

\section{Discussion}

Comparative analysis of Histopathology results with cytological diagnosis.

The follow up biopsy (histopathology) results were considered as gold standard. In our study we had follow up biopsy results for 157 cases out of total 211 cytology samples.

Our study had a sensitivity of $(78.1 \%)$ and a specificity of $(97.7 \%)$. Other series showed a sensitivity of 40 
91\% and a specificity of $90-94 \%$ in the detection of GI tract malignancies by cytological methods when compared with histology reports $[9,10]$. In our study, the test had a positive predictive value $(98.9 \%)$ but a negative predictive value $(62.7 \%)$.

4 cases which were reported as positive for malignancy in cytology with follow up biopsy showing negative for malignancy was not included as false-positive result. Because, the review of the cytology slides showed malignant features and even that patient's clinical and endoscopic findings were suggestive of malignancy. Therefore, most probably the subsequent biopsy would have been taken from a non representative area and hence in this case, cytological diagnosis proved to be effective even when the biopsy failed to reveal the malignancy.

We had 25 cases of false negative results and on reviewing these cases it was found that 18 cases showed only benign epithelial cells in sheets and clusters with well maintained polarity and no atypical cells found with 5 cases showing scant cellularity. Hence the possible explanation could be sampling error, where the sampling is obtained from a non representative area.

Other 7 cases showed poorly preserved and poorly spread smears (technical error) on which morphology and nature of the lesion cannot be commented upon. Atypical cells were seen in 6 cases but due to poor preservation and scant cellularity, no definite opinion was offered.

This error together with the sampling error had reduced negative predictive value $(62.7 \%)$ considerably in our study and if sampling error is excluded as it is technical error which depends on performing endoscopist, then the corrected negative predictive value and sensitivity will be $85.7 \%$ and $92.7 \%$ respectively. Whereas, Vidyavati $\mathrm{K}$ et al. observed a sensitivity of $98 \%$ in their study and recommend usefulness of brush cytology as a screening procedure and also stated that, definitive surgical treatment is rarely based on a positive or suspicious smear, the inclusion of the "suspicious" category alerts the clinician about the possibility of malignancy. Patient management is altered in these situations so that a repeat endoscopy and biopsy becomes mandatory [11].

The positive predictive value and specificity in our study is $98.9 \%$ and $97.7 \%$ which means in an adequate brush cytology smear, malignancy was never overdiagnosed. These figures along with the above corrected values substantiates the value of brush cytology in diagnosing GI tract malignancies and our study results are equivalent and even superior when compared with results of world literature[12, 13].

Finally, the diagnostic yield (defined as the proportion of tumours diagnosed by brush cytology as a percentage of the total number of neoplasms found at histology expressed as a percentage) was calculated as $92.9 \%$.

\section{Conclusion}

Brush cytology is a safe, easy and rapid method of diagnosing gastric malignancies. It is a useful adjunct in the diagnosis of gastric malignancies and should be considered as a routine method in combination with biopsy. Multiple repeated endoscopies are recommended in cases of positive cytology and negative biopsy to rule out or confirm malignancy.

\section{Funding:Nil. Conflict of interest: Nil. Permission for IRB: Yes}

\section{References}

1. National cancer registry programme, consolidated report of population based cancer registries 2001- 2004. http://www.icmr.nic.in/ncrp/report_pop_200104/Chapter\%2001-05\%20Pages\%201\%20to\%2053.pdf

2. Mueller PR, vanSonnenberg E. Interventional radiology in the chest and abdomen. $\mathrm{N}$ Engl $\mathrm{J}$ Med. 1990 May 10;322(19):1364-74.

3. Charboneau JW, Reading CC, Welch TJ. CT and sonographically guided needle biopsy: current techniques and new innovations. AJR Am J Roentgenol. 1990 Jan;154(1):1-10.

4. Xing GS, Geng JC, Han XW, Dai JH, Wu CY. Endobiliary brush cytology during percutaneous transhepatic cholangiodrainage in patients with obstructive jaundice. Hepatobiliary Pancreat Dis Int 2005; 4(1): 98-103.

5. Kaminsky DB. Aspiration biopsy in the context of the new Medicare fiscal policy. Acta Cytol. 1984 MayJun;28(3):333-6.

6. Young JA, Hughes HE, Lee FD. Evaluation of endoscopic brush and biopsy touch smear cytology and biopsy histology in the diagnosis of carcinoma of the 
lower oesophagus and cardia. J Clin Pathol. 1980 Sep;33(9):811-4.

7. Witzel L, Halter F, Grétillat PA, Scheurer U, Keller M. Evaluation of specific value of endoscopic biopsies and brush cytology for malignancies of the oesophagus and stomach. Gut. 1976 May;17(5):375-7.

8. Cook IJ, de Carle DJ, Haneman B, Hunt DR, Talley NA, Miller D. The role of brushing cytology in the diagnosis of gastric malignancy. Acta Cytol. 1988 JulAug;32(4):461-4.

9. Yang GC, Alvarez II. Ultrafast Papanicolaou stain. An alternative preparation for fine needle aspiration cytology. Acta Cytol. 1995 Jan-Feb;39(1):55-60.

10. Guidelines of the Papanicolaou Society of Cytopathology for fine-needle aspiration procedure and reporting. The Papanicolaou Society of Cytopathology
Task Force on Standards of Practice. Mod Pathol. 1997 Jul;10(7):739-47.

11. Vidyavathi K, Harendrakumar ML, Lakshmana Kumar YC. Correlation of endoscopic brush cytology with biopsy in diagnosis of upper gastrointestinal neoplasms. Indian J Pathol Microbiol. 2008 OctDec;51(4):489-92.

12. Gupta SC, Bisht D, Nigam DK, Singh PA. Fibreoptic endoscopy, endoscopic brush, biopsy imprint cytology and biopsy histology in lesions of upper gastrointestinal tract. Indian J Pathol Microbiol1984;27:229-40.

13. Sharma P, Misra V, Singh PA, Misra SP, Gupta SC. A correlative study of histology and imprint cytology in the diagnosis of gastrointestinal tract malignancies. Indian J Pathol Microbiol. 1997 Apr;40(2):139-46.

\section{How to cite this article?}

Ojha S, Naik L, Fernandes G, Joshi A, Kothari KS. Brush cytology and biopsy in the diagnosis of malignancy of gastrointestinal tract - A comparative study. Int J Med Res Rev 2015;3(10):1246-1250. doi: 10.17511/ijmrr.2015.i10.226. 